\title{
A note on stamen position and petal number in Loranthaceae
}

\author{
J. Kuijt ${ }^{1}$
}

Key words

Loranthaceae

New World

Old World

stamen position

\begin{abstract}
Stamen position in Loranthaceae is summarized in both the Old and New Worlds. In the former, stamens are inserted on petals at the same height in an individual flower, with very few exceptions that appear to be in basalmost genera only. In the Americas, much diversity exists in both the position and the within-flower shapes of stamens, phenomena that occur in many genera, Psittacanthus showing the greatest diversity. The dimorphic, or at least the biseriate condition is believed to be the plesiomorphic state. Some comments are added on petal numbers in the family.
\end{abstract}

Published on 8 October 2010
A number of studies in neotropical Loranthaceae in the last several decades have documented the fact that in many genera the stamens may be attached to subtending petals at two or even three different heights, and/or are of two different forms, as exemplified by Maracanthus (Kuijt 1976a), Oryctanthus (Kuijt 1976b), and many species of Cladocolea (Kuijt 1975) and Psittacanthus (Kuijt 2009). In the last-mentioned two genera, many species have all stamens attached at the same height, while numerous others have biseriate or even (in Psittacanthus) triseriate stamens. Stamens may or may not be dimorphic in Psittacanthus and some other genera.

In dioecious species of Phthirusa a double dimorphism exists, viz. sexual dimorphism superimposed upon within-flower dimorphism. In the related genus Dendropemon, as well as in an as yet undescribed Phthirusa species from Amazonian Brazil, stamens are alternatingly fertile and sterile (Kuijt, in prep.); the coexistence of staminodia and fertile stamens within a flower is not known elsewhere in Loranthaceae.

The striking fact is that, with a couple of exceptions, these phenomena are unknown in the extensive Old World Loranthaceae, where all stamens of a flower are placed at the same height and are essentially of the same shape. Interestingly, the exceptions are the two basal, monotypic genera Atkinsonia and Nuytsia, plus Muellerina and, to a very slight extent, Cecarria (B.A. Barlow, pers. comm.). All four of these genera belong to the putatively relictual southern loranths illustrating the presumed Gondwanan origins of the family (Barlow 1983). The basal position of at least Atkinsonia, and Nuytsia, as well as Gaiadendron of the New World, has recently been confirmed by molecular methods (Vidal-Russell \& Nickrent 2008), even though a close affinity to the other two genera is not indicated.

The relevant facts in the Old World, however, have not been clearly enunciated or illustrated in the literature, and the present note attempts to rectify this situation, focusing especially on the three basalmost monotypic genera of the family, viz., Atkinsonia, Nuytsia, and Gaiadendron. The first two genera are endemic to Australia (Blue Mountains and the Perth area, respectively), while Gaiadendron ranges from Bolivia to Nicaragua, with an outlier in some mountain tops of eastern Venezuela as far as Mount Roraima (Rizzini 1982, Kuijt 2007). These three genera

\footnotetext{
${ }^{1}$ Department of Biology, University of Victoria, Victoria V8W3N5, Canada; e-mail: jkuijt@uvic.ca.
}

are regarded as sister taxa to the remaining members of the family (Vidal-Russell \& Nickrent 2008); relevant details are given below.

\begin{tabular}{|c|c|c|c|}
\hline & $\begin{array}{l}\text { Atkinsonia } \\
\text { (Fig. 1b-d) }\end{array}$ & $\begin{array}{l}\text { Nuytsia } \\
\text { (Fig. 1a) }\end{array}$ & $\begin{array}{l}\text { Gaiadendron } \\
\text { (Fig. 1e,f) }\end{array}$ \\
\hline \multicolumn{4}{|l|}{ petals } \\
\hline number & 7 & 6 or 8 & mostly 7 \\
\hline length & $4 \mathrm{~mm}$ & c. $8 \mathrm{~mm}$ & $9-35 \mathrm{~mm}$ \\
\hline \multicolumn{4}{|l|}{ anthers } \\
\hline $\begin{array}{l}\text { length } \\
\text { position }\end{array}$ & $\begin{array}{l}1 \mathrm{~mm} \\
\text { mostly in an upper } \\
\text { series, at least one } \\
\text { placed lower }\end{array}$ & $\begin{array}{l}2 \mathrm{~mm} \\
\text { at two different } \\
\text { heights }\end{array}$ & $\begin{array}{l}2-3 \mathrm{~mm} \\
\text { at three different } \\
\text { heights }\end{array}$ \\
\hline
\end{tabular}

While the flowers of Atkinsonia and Nuytsia are relatively uniform in size, those of Gaiadendron are unusually variable in length. For that reason, two extremes are here illustrated. The mature bud illustrated in Fig. 1e is $35 \mathrm{~mm}$ long, while that of Fig. $1 \mathrm{f}$ is no more than $9 \mathrm{~mm}$ long. It should also be mentioned that filament length and attachment of all genera mentioned are difficult to ascertain.

I have not been able to inspect Muellerina material, but rely on Barlow's (1966) statement that its stamens are unequal, and that its 4 species represent a primitive genus. Cecarria has slightly unequal stamens and, more tenuously, is also stated to be a primitive genus (Barlow 1974). I would add that two Chilean monotypic genera, Desmaria and Notanthera, also regarded as relictual (Barlow \& Wiens 1973, Barlow 1983), have 6 -merous flowers and biseriate stamens.

The above facts in the Old World, coupled with the situation in Gaiadendron, are of considerable interest, as they raise the question which of these conditions is ancestral, and which derived. The fact that isomorphic stamens, or anthers at the same height, occurs on none of the above-mentioned genera of presumed Gondwanan origin strongly suggests that at least biseriate stamens represents a plesiomorphic state in the family. It should be noted, however, that this leaves the uniformly isomorphic stamens of Asiatic and African genera and some neotropical Loranthaceae unexplained; it is very difficult to suggest ecological conditions favouring the evolution of uniseriate anthers.

(c) 2010 Nationaal Herbarium Nederland

You are free to share - to copy, distribute and transmit the work, under the following conditions:

Attribution: $\quad$ You must attribute the work in the manner specified by the author or licensor (but not in any way that suggests that they endorse you or your use of the work).

Non-commercia:

You may not use this work for commercial purposes.

For any reuse or distribution, you must make clear to others the license terms of this work, which can be found at http://creativecommons.org/licenses/by-nc-nd/3.0/legalcode. Any of the above conditions can be waived if you get permission from the copyright holder. Nothing in this license impairs or restricts the author's moral rights. 

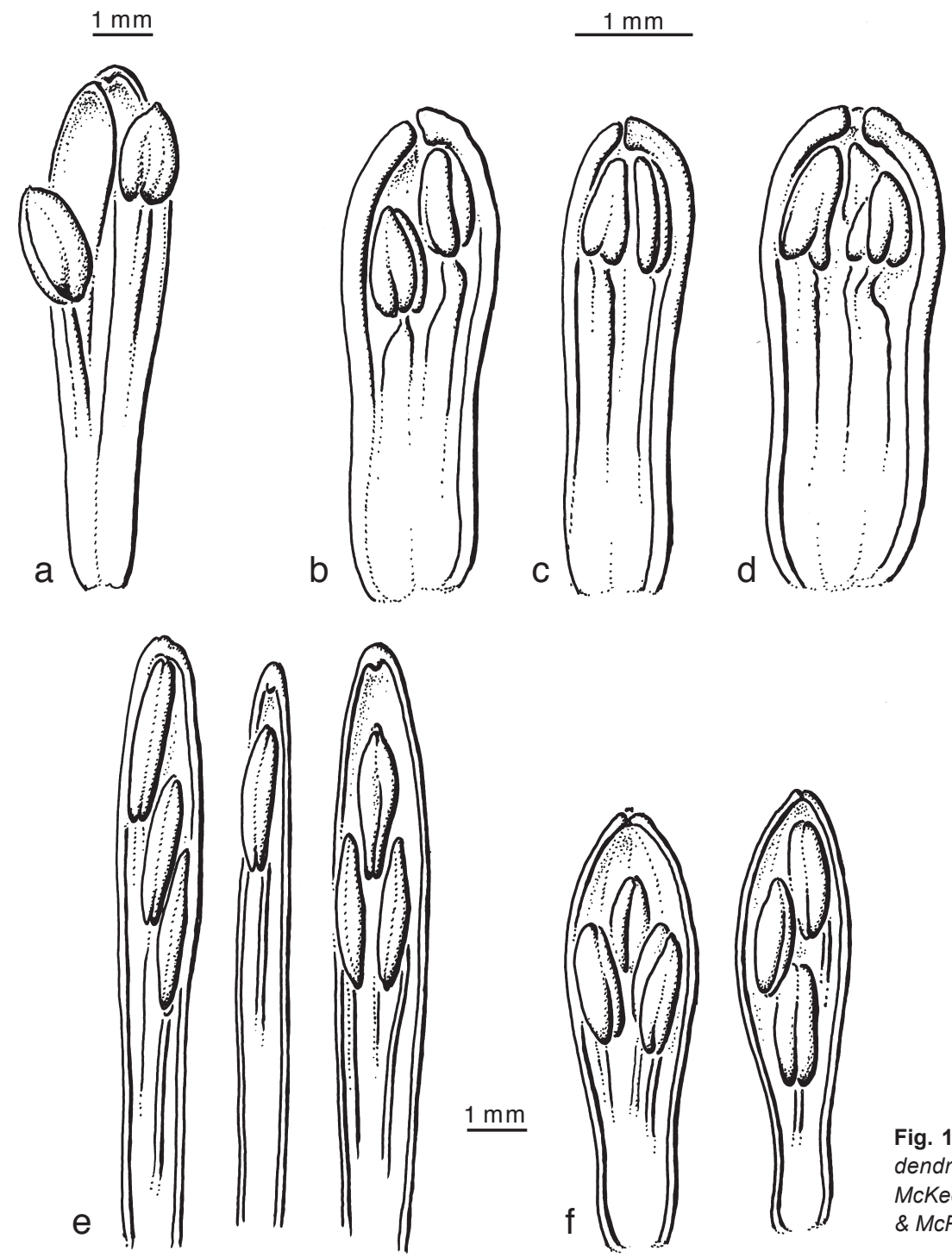

Fig. 1 Floral dissection. a. Nuytsia; b-d. Atkinsonia; e, f. Gaiadendron (upper half of petals only) (a: Saffrey 153, US; b-d: McKee 883, US; e: Palacios \& Van der Werff 3944, LEA; f: Roldán \& McPherson 1145, LEA)

Barlow (1983: 21) listed a number of putatively primitive or ancestral attributes for Loranthaceae generally, among which a 6-merous perianth. While the great majority of species in the family have 6 petals, this is not true for the genera Atkinsonia, Gaiadendron, and Nuytsia, as listed above. I already pointed out in Kuijt (1964) that Gaiadendron flowers in Costa Rica have mostly 7 petals, an uncommon number in angiosperms. The present note demonstrates that this is probably generally also true in more southern populations of this species, irrespective of the size of the flower. In Nuytsia, I have found that flowers with 6 as well as 8 petals exist. My material of Atkinsonia was limited, but showed 7 petals in each flower seen. In all these cases, the stamens were of variable position on the subtending petals. It may be, therefore, that these unusual petal numbers must be considered as an additional plesiomorphic feature in the family.

It should, finally, be pointed out that dimorphism and positional variation of stamens in Loranthaceae represents an extremely unusual condition in angiosperms in that these stamens occur, in each case, on a single whorl of perianth segments. Positional stamen differences on members of different perianth whorls are of a fairly common occurrence in other angiosperm families, both in monocots and eudicots, as in Liliaceae and Brassicaceae, but in Loranthaceae all perianth members involved belong to the same floral whorl. I am not aware of a comparable situation beyond Loranthaceae except perhaps in Olacaceae (Kuijt 1969).

\section{REFERENCES}

Barlow BA. 1966. A revision of the Loranthaceae of Australia and New Zealand. Australian Journal of Botany 14: 421-499.

Barlow BA. 1974. A revision of the Loranthaceae of New Guinea and the south-western Pacific. Australian Journal of Botany 22: 531-621.

Barlow BA. 1983. Biogeography of Loranthaceae and Viscaceae. In: Calder DM, Bernhardt P (eds), The biology of mistletoes: 19-46. Sydney, Academic Press.

Barlow BS, Wiens D. 1973. The classification of the generic segregates of Phrygilanthus (= Notanthera) of the Loranthaceae. Brittonia 25: 26-39.

Kuijt J. 1964. A revision of the Loranthaceae of Costa Rica. Botanische Jahrbücher für Systematik, Pflanzengeschichte und Pflanzengeographie 83: $250-326$.

Kuijt J. 1969. The biology of parasitic flowering plants. University of California Press, Berkeley \& Los Angeles.

Kuijt J. 1975. The genus Cladocolea (Loranthaceae). Journal of the Arnold Arboretum 56: 265-335.

Kuijt J. 1976a. Maracanthus, a new genus of Loranthaceae. Brittonia 28 . 231-238.

Kuijt J. 1976b. Revision of the genus Oryctanthus (Loranthaceae). Botanische Jahrbücher für Systematik, Pflanzengeschichte und Pflanzengeographie 95: 478-534.

Kuijt J. 2007. Loranthaceae. In: Jansen-Jacobs MJ (ed), Flora of the Guianas 105b: 7-69. Royal Botanical Gardens, Kew.

Kuijt J. 2009. Monograph of Psittacanthus (Loranthaceae). Systematic Botany Monographs 86: 1-361.

Rizzini CT. 1982. Loranthaceae. In: Luces de Febres Z, Steyermark JA(eds), Flora de Venezuela 4, 2: 7-316.

Vidal-Russell R, Nickrent DL. 2008. Evolutionary relationships in the showy mistletoes (Loranthaceae). American Journal of Botany 95: 1015-1029. 